\title{
Prevalence and Risk Factors of Trypanosoma evansi Infection and Classification of Vectors in Camels in Tamboul localty, Sudan
}

\author{
Mohammed, Ali M. Osman ${ }^{1}$, Altraifi, F. Gissmalla ${ }^{2}$, Juma, $\mathbf{Y}^{2}$, Fangama, M.I.M. ${ }^{3}$, \\ Mohammed, A. Abdalla ${ }^{1}$ and Siham, E. Suliman ${ }^{1}$ \\ ${ }^{1}$ Sudan University of Science and Technology College of Graduate Studies, \\ Khartoum, Sudan \\ ${ }^{2}$ Al-Gezira University, Faculty of Veterinary Medicine-Animal Researches Resources \\ Corporation \\ ${ }^{3}$ Ministry of Health, Qatar Public Health Department \\ *Corresponding author
}

\section{A B S T R A C T}

Keywords

Trypanosoma

evansi, Camel,

Trypanosomiasis,

Giemsa stain

Article Info

Accepted:

10 July 2020

Available Online:

10 August 2020
Surra, a vector borne disease caused by Trypanosoma evansi, is considered as a major enzootic disease mainly for the dromedary camel. Therefore, a crosssectional study was conducted to determine the prevalence of camel trypanosomasis and to assess the distribution and dynamics of the vectors responsible for transmission of the disease in camels in Tamboul market, Gezira state, Sudan from December 2018 to November 2019. A total of 213 blood samples were collected and thin blood smears stained by Giemsa and the Buffy coat (Haematocrit Centrifugation technique (HCT)) were used to detect the parasite. Questionnaire was designed and include age, sex, breed, body condition and seasons of animals The positives rate was $11(5.2) \%$ in both method. This study demonstrated that there is no difference between the thin smear and the buffy coat by using Roc curve test in diagnosing this parasite. The study revealed that there was no relationship between the disease and all risk factors $(p \leq 0.05)$. Concerning density of tabanus flies, NZI traps were used for collection of the flies through the year to identify the type of flies in this area, where 181 flies were collected, 75 Tabanid agrestis, 74 Tabanus sufis and 32 Tabanus teaniola. The largest number of Tabanus sufis (30\%) was captured in April, followed by the Tabanus agrestis (22.6\%) in October and Tabanus taeniola (21.8\%) in November. Diagnosis of trypanosomasis of camels by microscopic examination and haematocrit centrifugation are ease test and quick methods for detection of the parasite and identification of the vectors of importance because the disease leading to much greater loss amongst health and productivity. 


\section{Introduction}

Sudan is one of the large African countries with an area of about 1.8 million $\mathrm{km} 2$ and 30 million human populations. It is a predominantly agricultural country with a large development potential (MARF, 2014). Agricultural land is estimated as more than 800 million hectare. Camels (Camelus dromedarius) are important animals. They play an important role in sustainable agricultural resources for millions of people in the arid and semi-arid zones. Camels also provide milk, meat, wool and are used for water traction and the bear of burden. Moreover, the exportation of camels contributes to foreign currency earnings (Abd-Elmajid., 2000).

According to FAO (2008), Sudan ranks second, after Somalia, in camels' population. The Camel population was estimated at three millions, distributing in Northern Kordofan and Darfur in the west and the Red sea, Kassala and Butana in the East (Abd-Elmajid, 2000).

Parasitic diseases in the tropics are responsible for great losses (Soulsby, 1982). Livestock disease is among the major factors that affect the production and productivity having negative effects on the health of the livestock. The presence of diseases caused by haemoparasites is broadly related to the presence and distribution of their vectors.

One of the most prevalent protozoan parasite in Sudan in camels is Trypanosoma evansi $(T$. evansi) has a large diversity of mammalian hosts. It can be found in intra- and extravascular fluids of mammals and causes the surra disease in Africa, Asia, Europe and Latin America (Desquesnes, 2008).

Surra constitutes one of the major veterinary problems worldwide (Omer, 2004). Infection with $T$. evansi leads to high mortality and morbidity rate in camel's population. Additionally, since 2008, it is stated that the presence of surra in any area should be reported to the OIE (2008).

Concerning zoonotic impact, Joshi et al., (2005) reported the first human trypanosomiasis caused by T.evansi in India which make it a potential human pathogen.

Tsetse fly is considered as the main vector of animal trypanosomiasis, however, $T$. evansi is transmitted mechanically, non-cyclically, by Haematophagus flies such as: Tabanus, Stomoxys, Lyperosia, and Chrysops. Because the trypanosomes remain infective for only a short period, such transmission occurs when the biting flies feed on more than one host and transmit the organism through their mouse parts (Desquesnes, 2013).

T. evansi affects the health, working capacity and productivity of dromedary camels however, clinical signs are not pathognomonic therefore, diagnosis must be confirmed by laboratory methods. Additionally, assessment of the prevalence of T. evansi would be better performed by means of parasitological (Giemsa stained thin smear), serological and molecular tests (Singh, 2004).

The control of trypanosomiasis can be performed either by using chemotherapy or by vector control (Abd-Elmajid, 2000) which is necessary for improved camel health and productivity. This cannot be attained unless several investigations on the epidemiology of the disease are made.

The objectives of this paper to determine the prevalence of Trypanosoma evansi in camels and associated risk factors and also density of tabanid flies as vector of the disease. 


\section{Material and Methods}

\section{Study area}

This study was carried out at Tamboul livestock market, from December 2018 to November 2019. The district is located at latitude $14^{\circ} 52^{\prime} \mathrm{N}$ and longitude $33^{\circ} 31^{\prime} \mathrm{E}$. in east part of Gezira state around $150 \mathrm{~km}$ south East Khartoum.

\section{Study design and sample size}

Systemic random sample was used to select the individual of study. The sample size was calculated according to the formula described by Thursfiled (2007) based on previous prevalence $(4.8 \%$. \%) of trypanosomiasis of camel in the Sudan reported by Alsrag (2017) with $95 \%$ confidence interval and 5\% desired absolute precision. The samples calculated were 213 samples.

\section{Collection of blood samples}

Whole blood samples from 213 camels were collected from the jugular vein into a heparinized vacutainer tube $(5 \mathrm{ml})$ in Tamboul market. The tubes were labeled with a number and kept in ice box and then were transported immediately to the laboratory of Faculty of Veterinary Medicine _ Butana University. At the same time the questionnaire was designed and including the information the information regarding age, sex, breed, body condition, and sources of animals were obtained by asking of the owner.

\section{Diagnosis of Trypanosomiasis}

\section{Thin blood smears}

The Thin blood smears were performed as described by Murray et al., (1977). The smears were stained using $4 \%$ diluted Giemsa for 30 minutes. The stained slides were examined under oil immersion objective lens $(100 x)$ to detect and identify the Trypanosoma species based on the morphological characters.

\section{Microhaematocrit centrifugation technique (MHCT)}

A heparinized capillary tube $(75 \times 1.5 \mathrm{~mm})$ was filled with blood until two thirds its size and then was sealed from one side using crestaseal. The tube was centrifuged for 4 minutes at $12,000 \mathrm{rpm} /$ minute using microhaematocrit centrifuge. After centrifugation, the capillary tube was placed on a microscopic slide and the interphase between the buffy coat layer and the plasma was examined under a microscope using $10 \mathrm{X}$ objective lens (Wernery et al., 2001). The contents of the capillary tube were gently spread onto a microscopic slide, and then covered with a coverslip. The slides were examined under a microscope for the presence of the motile trypanosome using 10x or 40x objective lenses (Murray et al., 1977).

\section{Collection of flies:}

Nzi trap was made from blue cotton, local white nylon mosquito netting and local matt black cotton cloth. The blue cloth was imported from Kenya (United Textile Industries Nairobi, Kenya) following ICIPE scientists (Mihok, 2002). Nzi trap was operated from dawn to dusk (0600-1800 h local time) each day for 4 consecutive days every month. Flies were collected (181 flies), killed by isolation in plastic bottles and transferred to the department of tsetse and control at Central Veterinary Research laboratory, Khartoum, where they were identified and counted.

\section{Statistical analysis}

The collected data were coded and entered 
into an Excel spreadsheet_ Microsoft Excel, 2007. Statistical analysis was performed using statistical package for the social sciences (SPSS), version 20 software. Percentage was used to calculate prevalence. Data were statistically analyzed using Chi-squared test to calculate degree of association between risk factors and prevalence of camel trypanosomiais. $95 \%$ confidence interval (CI) and $\mathrm{p} \leq 0.05$ was considered for statistically significant difference.

The comparison between the buffy coat and Giemsa stained smears including the sensitivity and specificity was performed using Roc curve.

\section{Results and Discussion}

The prevalence of trypanosomiasis in camel in Tamboul district

A total of 213 blood samples were examined for tryponosomiasis using stained smear and buffy coat methods were prevalence 11 samples found to be positive to the disease and over all infection rate was $5.2 \%$. (Table.1)

\section{Risk factors analysis}

As shown in Table 1, all risk factors were not associated with risk factors $(\mathrm{p} \leq 0.05)$.

\section{Rock curve test}

No difference was found between buffy coat and stained smear techniques in detecting trypanosomes when Rock curve Test was used.

\section{Classification of vectors}

The most abundant species of biting flies during the whole collection period was T.sufis (31\%) and highly aburdant during April and least abundant in May and Jun and T. agrestis
(22.6\%) during October. But $T$. taeniola $(21.5 \%)$ was increased during November (Table.2).

Trypanosomiasis is a disease affecting the immune system of the host animal. T. evansi as purely extracellular parasites are permanently confronted with the multiple components of the host' immune system ranging from innate to adaptive immune defenses (Eyob and Matios, 2013.).

In the present study an overall prevalence of trypanosomiasis was $5.2 \%$. This prevalence indicates the importance of the disease in the area, our result in this study is in line with the study which was carried out by Khalid (2015) who surveyed camel trypanosomiasis in Butana, Gedarif state, where the prevalence was $5.1 \%$.On the other hand, the result was higher than that demonstrated by Alsaraj (2017), where the prevalence was $4.8 \%$ and lower than that reported by Ibrahim (2015) where the prevalence was $6.08 \%$.This difference may be attributed to the difference in sample size.

The univariate analysis of the risk factors showed that there was no statistical significant ( $p$-value $<0.25)$ association of the studied factors with trypanosomiasis infection.

In the present study a high infection rate was found in old camels $>10$ years $(6.5 \%)$ and young <5years (5.2\%)than the adult 5-10 years $(3.8 \%)$, this result in agreement with that of Basaznew Bogale et al., (2012).The higher prevalence of trypanosomiasis in old camels might be due to the heavy stress through their transportation and long-term exposure under poor management and prolonged exposure to the vector, young animals become susceptible to infection after weaning and thus losing the maternal immunity which transferred to them through colostrum. 
Table.1 Summary of univairate analysis of the risk factors associated with trypansomasis infection in camels $[n=213]$ in Tamboul, Gezira state, Sudan

\begin{tabular}{|c|c|c|c|c|c|}
\hline Risk factors & No. tested & No. +ve \% & D.f & Chi & P value \\
\hline \multicolumn{6}{|l|}{ Age } \\
\hline Young $<5$ & 58 & $3(5.2 \%)$ & 2 & 0.554 & 0.758 \\
\hline Adult 5-10 & 78 & $3(3.8 \%)$ & & & \\
\hline Old $<10$ & 77 & $5(6.5 \%)$ & & & \\
\hline \multicolumn{6}{|l|}{ Sex } \\
\hline Female & 165 & $10(6.1 \%)$ & & & \\
\hline Male & 48 & $1(2.1 \%)$ & 1 & 1.201 & 0.273 \\
\hline \multicolumn{6}{|l|}{ Breed } \\
\hline Butana & 51 & $4(7.8 \%)$ & 3 & 2.574 & 0.462 \\
\hline Darfur & 85 & $2(2.4 \%)$ & & & \\
\hline Kassala & 66 & $4(6.1 \%)$ & & & \\
\hline Kenana & 11 & $1(9.1 \%)$ & & & \\
\hline \multicolumn{6}{|c|}{ Body condition } \\
\hline Fat & 38 & $1(2.6 \%)$ & 2 & 0.929 & 0.628 \\
\hline Normal & 127 & $8(6.3 \%)$ & & & \\
\hline Poor & 48 & $2(4.2 \%)$ & & & \\
\hline \multicolumn{6}{|l|}{ Season } \\
\hline Dry hot & 71 & $5(7.0 \%)$ & 2 & 0.767 & 0.682 \\
\hline Wet cold & 71 & $3(4.2 \%)$ & & & \\
\hline Cold dry & 71 & $3(4.2 \%)$ & & & \\
\hline
\end{tabular}


Table.2 Relative abundance of biting flies [n=181] collected around Tambuol market at species level during the year

\begin{tabular}{|c|c|c|c|c|c|}
\hline Month & T.sufis & T.taeniola & T.agrestis & Mean & S .d \\
\hline January & $4(5.4 \%)$ & $2(6.25 \%)$ & $5(6.66 \%)$ & 2.1 & .94 \\
\hline February & $7(9.4 \%)$ & $5(15.6 \%)$ & $7(9.33 \%)$ & 2 & .88 \\
\hline March & $8(10.8 \%)$ & $2(6.25 \%)$ & $3(4 \%)$ & 1.6 & .87 \\
\hline April & $23(31 \%)$ & $3(9.37 \%)$ & $14(18.7 \%)$ & 1.77 & .95 \\
\hline May & $0(0 \%)$ & $0(0 \%)$ & $1(1.3 \%)$ & 3 & 0 \\
\hline June & $0(0 \%)$ & $0(0 \%)$ & $4(5.33 \%)$ & 3 & .000 \\
\hline July & $2(2.7 \%)$ & $1(3.12 \%)$ & $5(6.66 \%)$ & 2.37 & .92 \\
\hline August & $2(2.7 \%)$ & $0(0 \%)$ & $1(1.3 \%)$ & 1.66 & 1.2 \\
\hline September & $2(2.7 \%)$ & $4(12.5 \%)$ & $5(6.66 \%)$ & 2.27 & .79 \\
\hline October & $2(2.7 \%)$ & $2(6.25 \%)$ & $17(22.6 \%)$ & 2.7 & .64 \\
\hline November & $15(20.27 \%)$ & $7(21.8 \%)$ & $6(8 \%)$ & 1.67 & .82 \\
\hline December & $9(12.16 \%)$ & $6(18.7 \%)$ & $7(9.33 \%)$ & 1.9 & .87 \\
\hline Total & 74 & 32 & 75 & & \\
\hline
\end{tabular}

Females in this study had higher prevalence $(6.1 \%)$ than male $(2.1 \%)$. Similar results in epidemiological investigation were obtained by Najira (2003) in Kenya and Eldaw (2009) in Sudan. This observation may be explained by the stress induced by pregnancy and lactation (Ataib et al., 2015). Moreover, the majority of animals slaughtered during this study period were females.

As for breed, the higher infection rate was detected in Kenana (9.1\%) and Butana (7.8\%), than Darfur (2.4\%) and Kassala $(6.1 \%)$ breeds. This result could be due to the fact that Kenana breed is used for transportation and work than other breeds, and Kenana breed was the lower number of camels examined from this area.

Regarding body condition in this study, the infection rate was higher $(6.3 \%)$ in animals in normal body condition, than in fat $(2.6 \%)$ and poor $(4.2 \%)$ body conditions. This could be due to the chronic nature of the disease.
Concerning seasonal distribution, our results showed that the prevalence of camels' infection was high in dry hot season $(7.0 \%)$, compared with the wet cold $(4.2 \%)$ and drycold season (4.2\%). This could suggest that these animals may become infected by the end of wet cold season and during the dry cold when the highest fly count that acts as $T$. evansi vectors which is usually expected during the rainy season. The high prevalence in dry hot season could be explained by the fact that the owners in Butana usually take their animals in this season to the riverine, Dindir national park or even to the Ethiopian border areas which are also favourable grounds for these flies.

In this study examination of camels in Tamboul market with stained smear revealed the animals were infected $(5.2 \%)$ and also the buffy coat technique $(5.2 \%)$, this result indicates that the stained smear is specific as well as buffy coat technique is diagnosing 
method of camel trypanosomiasis which is also attributed to the good handling of the sample when preparing it at the laboratory.

In this study, a few number of Tabanus species were collected, which may probably be justified to the low prevalence of Trypanosoma evansi in the study area. The presence of Tabanus species through the year ensures that the transmission of the parasite occurs wherever there is co-existence of reservoir hosts and susceptible hosts. Sporadic occurrence of the disease during the dry season and outbreaks during the rainy season has been reported tobe associated with the abundance of Tabanus species (Njriu et al., 2002).However, the efficiency of the different flies in transmitting Trypanosoma evansi is reported to vary in different geographic conditions and is also dependent on the interval between two successive feeds and the intensity of the flies ${ }^{\text {ee }}$ challenge (Lukins, 1998).

\section{References}

Abd-Elmajid, A. A. (2000). The one humped camels in the Sudan" 1 edition ACSAD, Damascus.

Alsrag, M .E. (2017). Prevalence and Risk factors of Trypanosoma evansi infections in Slaughtered Camelsin Tamboul Slaughterhouse, Sudan. M.V.SC. Dissertation, SUST.

Altayib, Mohammed; Mezene Woyessa, Tadesse Brihanu and AdemHiko. (2015). Cross Sectional Study of Camel Trypanosomiasis in Babile District, Eastern Hararghe Zone, Oromia Regional State, Eastern Ethiopia. Academic Journal of Animal Diseases 4(2): 112-117.

Basaznew Bogale, Ferew Kelemework and Mersha Chanie. (2012). Trypanomosis in Camel (Camelus dromedarius) in Delo-Mena District, Bale Zone, Oromia
Region, Southwest Ethiopia. Acta Parasitologica Globalis 3 (1): 12-15.

Desquesnes, M; Bossard, G; Patrel, D; Herder, S; Patout, O; (2008). First outbreak of Trypanosoma evansi in camels in metropolitan France. Vet Rec., 162:750-752.

Desquesnes, M; Holzmüller, P; Lai, D.H; Dargantes, A; Lun, Z.R; Jittaplapong. S. (2013). Trypanosoma evansi and surra: a review and perspectives on origin, history, distribution, taxonomy, morphology, hosts, and pathogenic effects. Bio Med Res Int, 1-22.

Eldaw, A, A. (2009). Epedimiological studies of Trypanosa evansi infection and Gastrointestinal Nematodes in camel. M.V.Sc. Dissertation, U of K., Sudan.

Eyob, E. and Matios, L. (2013). Review on camel trypanosomiasis (Surra) due to Trypanosoma evansi: Epidemiology and host response) Journal of Veterinary Medicine and Animal Health. Academic journals. JVMAH.

FAO, (2008). Food and Agricultural Organization of the United Nations (FAO).Food and World camel population FAO statistics.

Ibrahim, Abdalla M., Ismail, Ahmed A., A/Majid, Ali M., A/Rahman, Ahmed H., Angara, Tamador-Elkhansa E. (2015). Packed Cell Volume Values of Sudanese Camels Grazing Under Open System: With Emphasis to its Importance for "Guffar" Management and Control.

http://repository.sustech.edu/handle/ 123456789/16392.

Joshi, PP; Shegokar; VR; Powar; RM; Herder; S; Katti; R. (2005). Human trypanosomiasis caused by Trypanosoma evansi, in India: the first case report. Am J Trop Med Hyg., 73:491-495.

Khalid, A. (2015). Prevalence and Risk factors of camel trypanosomiasis in 
Butana area Gedarrif State. M.V.Sc. Dissertation, SUST.Sudan.

Luckins, A. G. (1998). Epidemiology of Surra: Unanswered Questions. $J$. Protozool. Res. 8, 106-119.

MARF, (2014). Ministry of animal resources and fisheries

Mihok, S. (2002). The development of multipurpose trap (the Nzi) for tsetse and other biting flies. Bulletin of Entomological Research. 92(5): 385403.

Murray, M., Murray, P. K. and Mclntyre, W. I. M. (1977). An improved parasitological technique for the diagnosis of African trypansomosis. Trans. R. Soc. Trop. Med. Hyg. 71: 325326.

Najira, J. M., Bett, B., Karanja, S. M. and Njiri, E. N. (2003). Evaluation of antigen and antibody rapid detection test for T. evansi in camels in Kenya. Vet. Parasitool, 114(2):131-41. OIE. (2008). Manual of Diagnostics for terrestrial animals, edit. OIE(2013).Terrestrial Manual chapter,2.4.18.

Njiru, Z., O. Bett, I. Ole-Mapeny; J. Githiori; J. Ndung'u (2002). Trypanosomiasis and helminthosis in camels: comparison of ranch and traditional camel management systems in Kenya. $J$. Camel Pract. Res. 55, 67-71.

Omer RA; Elamin, SMM; El Nahas, AE. Aradaib, IE. (2004). PCR for detection of Echinococus granulosus hydatid cysts collected from camels (Camelus dromerarius). Sudan J Vet Sci. Anim. Husb. 43: 139-143.

Singh, N; Pathak, KML; Kumar, R, (2004).A comparative evaluation of parasitological, serological and DNA amplification methods for diagnosis of natural Trypanosomae vansi infection in camels. Veterinary Parasitology., 126:365-373.

Soulsby, E. J. L. (1982). Helminthes, Arthropods and Protozoa of Domesticated Animals.7th edition. Billier. Tindall-London: 532-533.

Thrusfield, M. (2007). Veterinary Epidemiology. 3rd edition (C) chapter 13 Survey page 233, by Blackwell Science Limited, USA, Pp.: 180-181, 224-225.

Wernery, U., Zachariah, R., Moford, J. A. and Luckin, T. (2001). Preliminary evaluation of diagnostic tests using horses experimentally infected with $T$. evansi. Vet. J. 161(3): 287-300.

\section{How to cite this article:}

Mohammed, Ali M. Osman, Altraifi, F. Gissmalla, Juma, Y, Fangama, M.I.M., Mohammed, A. Abdalla and Siham, E. Suliman. 2020. Prevalence and Risk Factors of Trypanosoma evansi Infection and Classification of Vectors in Camels in Tamboul localty, Sudan. Int.J.Curr.Microbiol.App.Sci. 9(08): 291-298. doi: https://doi.org/10.20546/ijcmas.2020.908.034 